Mohammad Bagher Khatibi Iran

Alireza Badeleh

Iran

Rouhollah Khodabandelou

Oman

\title{
A Bibliometric Analysis on the Research Trends of Gamification in Higher Education: 2010-2020
}

DOI: 10.15804/tner.2021.65.3.01

\begin{abstract}
Research on gamification shows that it has positive impacts on learning, performance, motivation, and engagement. To have a big picture on gamification research in higher education, a combination of bibliometric and thematic analysis was conducted. For this study, a total of 432 documents from 2010 to 2020 which have been indexed in Web of Science database are investigated. Additionally, the researchers analyzed a group of 10 articles to review how much contribution they had to the body of research. General tendencies in the way gamification has been changing or developing in academic literature were scrutinized from the perspective of a variety of different factors including the time the works were published; the areas of the research field; and the authors, organizations, countries, and co-authorship publishing the most number of works in the issue. The possible future applications and results for educational organizations and academicians, top academic decision-makers, and educationists are discussed.
\end{abstract}

Keywords: gamification, higher education, research trends, bibliometric.

\section{Introduction}

During the recent decades, instruction equaled to a teacher-centered physical classroom run traditionally. Using digital technology, student-centered instruction, 
which is more personalized, is being made possible. This evolution caused immediate knowledge development and skills mastery, expanded and enriched by a variety of technologically driven approaches (Ford \& Meyer, 2013). Learning in this situation would be interpreted as a constant mechanism to scan, analyze, and assess information and practices (Shute \& Ke, 2012). In this regard, education experts used gaming platforms to make learners more motivated and turn them into better educational achievers (Andrew \& Carman, 2014). This innovative sort of learning finds its place in the practice of teaching because of its entertaining nature, facilitating the interaction between students and instructors amusingly, creating a helpful and confident skill in the game player (Goethe, 2019; Reiners \& Wood, 2015).

The increasing student-centered instruction tends to move towards the application of instructional techniques and procedures in educational settings in the form of gamification, which is defined as the use of gaming platforms, combining the principles of beauty and entertainment, to make learners engaged and motivated; to help them achieve more and clarify learning problems (Kapp, 2012). The use of gamification at universities can provide learners with more incentives, which means that gamification makes the practice of learning more interesting, entertaining, and consequently, more helpful (Barber \& Smutzer, 2017). Nowadays, the first problem in educational settings is how to keep students engaged and involved in the learning process (Godwin, 2014). In this regard, gamification is one of the appropriate techniques to make students purpose-oriented and active participants in instructional tasks (Deterding et al. 2011, Kapp, 2012; Zichermann \& Cunningham, 2011). Lister (2015) believes that gamification is so influential and helpful that it attracts and maintains learners' mental focus in educational environments. It has become a popular method to improve motivation and performance (Kim, 2015). Strengthening educational processes can be defined as the successful integration of a curriculum release framework to improve student motivation, academic achievement, and attitude towards curriculum and programs (Yildirim, 2016). Regarding the significance of applying gamification in higher education, there should be a clear picture of its academic framework to exploit its research potentials. A review of the literature showed that unlike the increase in publishing lots of papers, research studies, books, theses, and dissertations on gamification, few studies are running a bibliometric analysis on the research trends of gamification in higher education in the last decade. Therefore, the current study is significant to illustrate and analyze the academic pathways of research domains of applying gamification in higher education. Considering papers published in a top database, we tried to depict the common research interests and concerns. In addition, we draw a map of an academic framework of the main trends in gam- 
ification. Web of Science is chosen for the current study because, in comparison with other research bases like Scopus, it has indexed high-quality books, journals, and papers on gamification.

\section{Statement of the Problem}

A review of the literature indicates that there have been some reviews, related to gamification. These reviews help academicians to develop a clear understanding of the general directions of gamification in the education context. Although the present study elaborated on points that are common with what we have in the literature, many new points about the issue are analyzed and discussed. In most of the studies, gamification was analyzed only in the educational and learning context. Furthermore, in none of the previous studies, higher education has been chosen as the context of the studies. Hence, there is a need for comprehensive research literature on higher education as the context of the study. As highlighted by Majuria et al. (2018), they did not put a limit on the data related to type or level of education. In this regard, there is a need for a study to focus on the educational level. Therefore, the current study tries to fill this gap by applying both Bibliometric and Thematic analysis to examine gamification in the higher education context.

The researchers believe that the outcomes of the present research should make an important contribution to the area of gamification related to education at higher levels. Hence, the main purpose of the present research was to examine the bibliometric characteristics of gamification research carefully from 2010 to 2020 . Within the bibliometric analysis, we were interested to identify some trends of the research field such as the number of articles, generative nations, organizations, and writers. The other goal of the research was to form a picture of the content of articles using bibliometric analysis and bibliometric mapping to discover the most innovative research terminologies described in the gamification research field as well as to conduct a chronological thematic analysis of research themes in the same period. To achieve the research objectives, the researchers tried to analyze the following issues: 1) the chronological evolution of the research; 2) the commonest types of documents published; 3 ) the most prolific countries/regions with the most publications; 4) the most active countries in co-authorship collaboration; 5) the most prolific source titles of the research production; 6) the top organizations with the most number of publications; 7) the most frequent author keywords/themes; 8) the highly cited publications; 9) the chronological order of the terms occurring in titles and abstracts of the sources. 


\section{Methodology of Research}

This study was conducted on 12 January 2021 in the Web of Science Core Collection (WoS) database using "Gamification" and "higher education" a search string in the published works for the period from 2010 to 2020. To perform the descriptive bibliometric analysis including the type of documents of the most generative years, writers, organizations, citations, and nations we used the WoS built-in functions Refine and Analyze. To generate landscapes and networks, the WoS full record with references was analyzed by the VOS viewer (van Eck, 2011; van Eck and Waltman, 2013) software. All common terms, such as "research", "file", "study", "respondents", "author", were excluded from the analysis. To use the parameters, the researchers used VOS viewer default parameters; however, we analyzed only abstracts and title terms occurring more than 100 times and author keywords occurring more than 10 times.

\section{Results}

\section{1) the chronological evolution of the research}

In the first step, the researchers were to analyze the chronological evolution of the researches for 10 years (2010-2020). In our analysis of the data set, among the 432 information sources, the highest frequency is related to the year 2020 with 107 articles $(24.7 \%)$ published in academic journals and proceedings on gamification. In addition, no articles or research projects were published in WoS in 2010 on gamification, noting the fact that the research area of gamification and its contribution to education was still unknown to researchers and educationists. The number of published documents increased sharply in 2013 (14 papers; 3.2 $\%)$ and it became more than six times larger after 6 years (in 2019), reaching 88 documents $(20.4 \%)$.

\section{2) the commonest types of documents published}

In the next step, the researchers tried to categorize the documents published on Gamification into different types. The most dominant document type of the research production on the research area of Gamification is 'Proceedings Papers', with 199 records (46\%). 'Articles' were the next dominant type, with 155 records (36\%). 'Conference Reviews' and 'Book Chapters' were the third and fourth types of documents with a record of 40 and 20 respectively. Another type of document, worth mentioning, is 'Review' ( $\mathrm{n}=11 ; 2.6 \%)$. The rest of the documents _ 'Books' 
(3), 'Notes' (3), and 'Editorials' (1) - are so infrequent that academicians do not usually take notice of them.

\section{3) the most prolific countries/regions}

According to the analysis, Spain outnumbers all the other nations in terms of the number of papers, with a total of 71 papers. It is then followed by the United Kingdom, and the United States - publishing about 37 documents. Then, another group of countries published about 25 documents including Portugal, Germany, Russia, and Mexico. The third group of countries - Australia, Brazil, Malaysia, Indonesia, and South Africa - published 15 papers on average.

With regard to citations, American papers $(n=432)$ come first among all nationalities and Spain comes second in this category $(n=337)$. The United Kingdom and Germany are the third and the fourth country (253 and 170 respectively) as far as the number of citations is concerned. In addition, academicians pay attention to the papers published in Malaysia, Australia, Portugal, and Russia because they enjoy an approximately large citation index ranging from 50 to 84 .

\section{4) the most active countries in co-authorship collaboration}

To have a more profound analysis of the data and discover the relation/ interaction of variables in this study, the researchers were to depict the strength of co-authorship collaboration (Figure 1.).

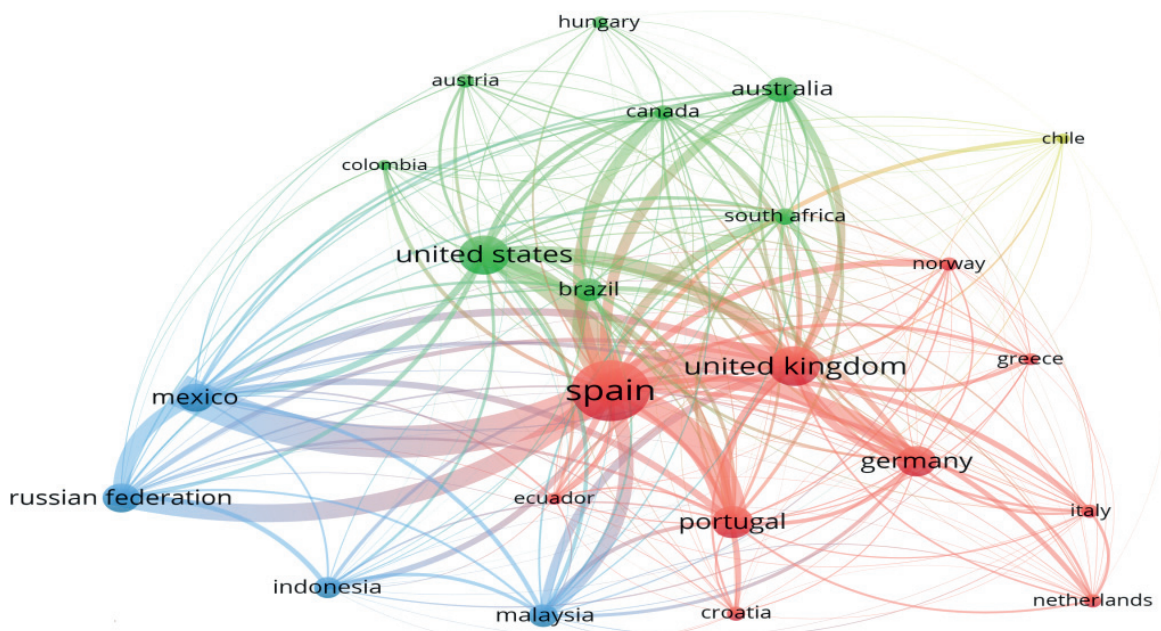

Figure 1. Co-authorship collaboration of the top countries 
Spain and the United Kingdom are far the most active in co-authorship collaboration (seen from the size of the circle), while these two countries form a circle of collaboration with Portugal and Germany. The frequency of co-authorship collaboration with each country is evident from the thickness of the line.

On the other hand, the United States, Australia, Canada, Brazil, and South Africa are also quite active in co-authorship, forming the second circle of collaboration; however, the collaboration is concentrated mainly on the European countries, namely, Spain, Germany, Portugal, Austria, etc. Some countries, like Canada, Greece, Norway, Chile, Italy, are showing a smaller number of co-authorship collaborations.

Furthermore, the third circle goes with countries like Russia, Mexico, Indonesia, and Malaysia, with Russia at the center of the circle. As it can be seen from the thickness of the lines in Figure 1, these three main circles collaborate in co-authorship.

\section{5) the most prolific source titles}

The source title of the research production was the other research trend in our sample. 'Lecture Notes in Computer Science' is the top journal that has published the majority of Gamification in higher education research production $(n=31)$. 'Proceedings of the European conference on games-based learning' and 'Communications in computer and information science' ( $\mathrm{n}=24$ and 23 respectively) are the second and third sources of data published on Gamification. 'ACM international conference proceeding series' and 'Advances in intelligent systems and computing' are the next following data source, having a range of 14 to 17 documents.

An interesting point about 'the source title' is that the journal of 'Computers and Education' has published the least number of papers on Gamification $(n=5)$ in our sample while enjoying the largest number of citations among all sources (213). It confirms the quality of the research projects published in the journal.'Proceedings of the European conference on games-based learning' is the second reliable source of data for academicians researching Gamification, having a citation index of 157. 'Journal of trends of Gamification in higher education' is the third referred journal among all data sources listed here (131).

\section{6) the top organizations with the most number of publications}

Regarding the prolific organizations, all the universities and academic societies, analyzed in the study, have about the same number of the publication. However, 'University of Duisburg-Essen, Germany' is significantly different from the other organizations because of its number of citations (52) which is dramatically larger 
than the relevant index in other universities. It confirms that the papers published by 'University of Duisburg-Essen, Germany' enjoy a high rate of reliability among academicians and researchers on Gamification.

\section{Thematic analysis}

\section{7) the most frequent author keywords/themes}

VOSviewer software is used to generate an all-scientific look based on keywords from the published keywords shown in Figure 2. According to the map and cluster combinations, five (5) clusters appear automatically in the scientific view. According to the most commonly used keywords found in these collections, we have written each collection with an appropriate research topic. In other words, the author's keywords were used to analyze the text. The author's keywords are very important because they represent key research and academic concepts. The network of events for the author's keywords is presented in Figure 2.

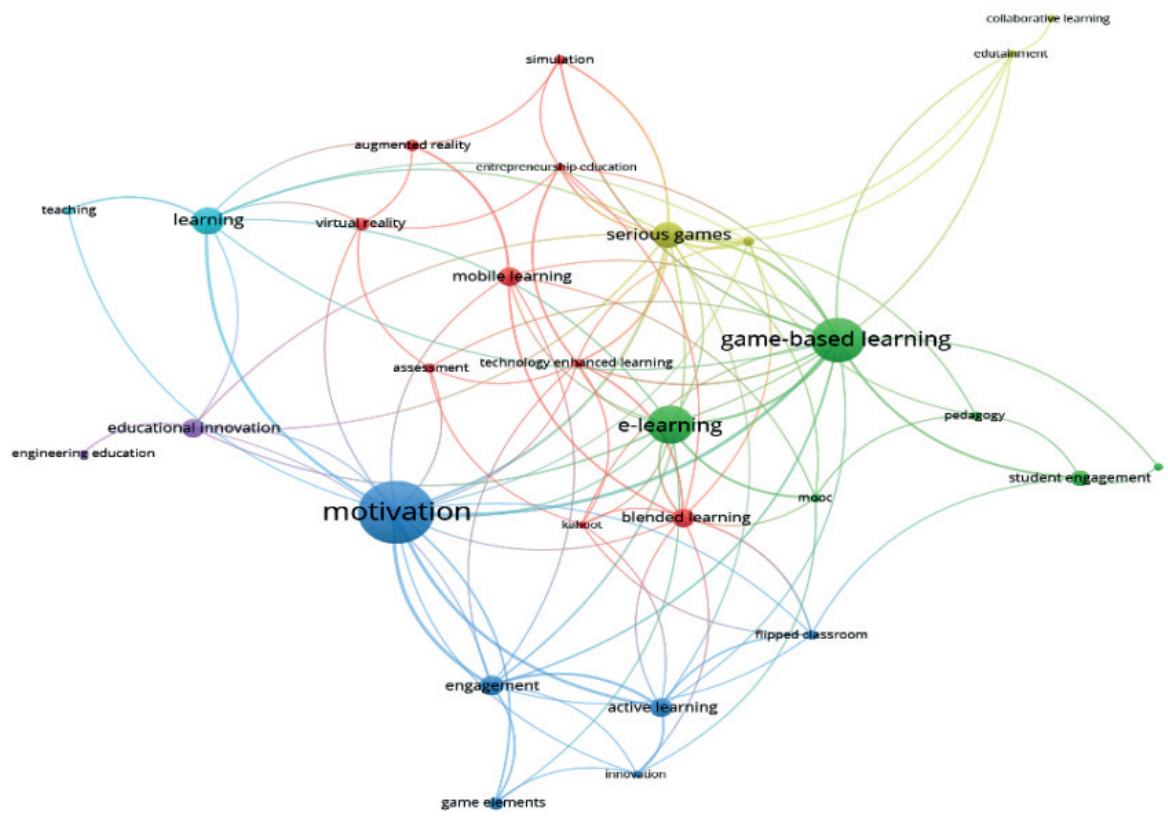

Figure 2. Author Keyword Co-occurrences Network $(\mathrm{n}>11)$. 
The authors who published their research articles on WoS used 3,715 different keywords of which 171 appeared more than 10 times. For this study, the most frequently used keywords are tagged in larger circles and those used less frequently are marked in smaller circles (Figure.2). By using the VOSviewer, keywords occur within 4 different clusters, separated by color, and representing the following themes:

a. Innovative Ways to Motivate and Engage Learners Studies (Blue Color): Learning, Teaching, Engagement, Active Learning, Game elements, Innovation, Flipped Learning.

b. Cutting Edge in Learning Assessment Approaches Studies (Red Color): Blended Learning, Virtual Reality, Assessment, Technology Enhanced Learning, Augmented Reality, Simulation.

c. Pedagogical Studies in Gamification, (Green Color): e-Learning, Student Engagement, Pedagogy, MOOC.

d. Engineering and Educational Innovation Studies (Violet Color): Educational Innovation, and Engineering Education.

e. Collaborative and edutaining Studies (Yellow Color): Serious games, Edutainment, Collaborative Learning.

The scientific overview, based on terms occurring in the publication's titles and abstracts presented in Figure 3. The authors used 29,485 different terms which 100 occurred more than 50 times. The most commonly used keywords are marked with larger circles, and less commonly used keywords are marked with a smaller circle (Figure. 3). In other words, based on the mapping and clustering approach, three (3) clusters emerged automatically in the scientific overview. According to the most frequently used keywords found in these clusters, we labeled each cluster with an appropriate research theme:

f. Course (red color): including terms such as activity, motivation, Engagement, challenge, group, game element, student engagement.

g. Technology (green color): including teacher, assessment, knowledge, teaching, educator, classroom, learning process, learner.

h. System (blue color): including development, Serious game, project

\section{$\underline{\text { Top citation papers }}$}

\section{8) the highly cited publications}

In order to provide research trends of Gamification in higher education, highly cited publications were analyzed. The purpose of this examination was to detect 


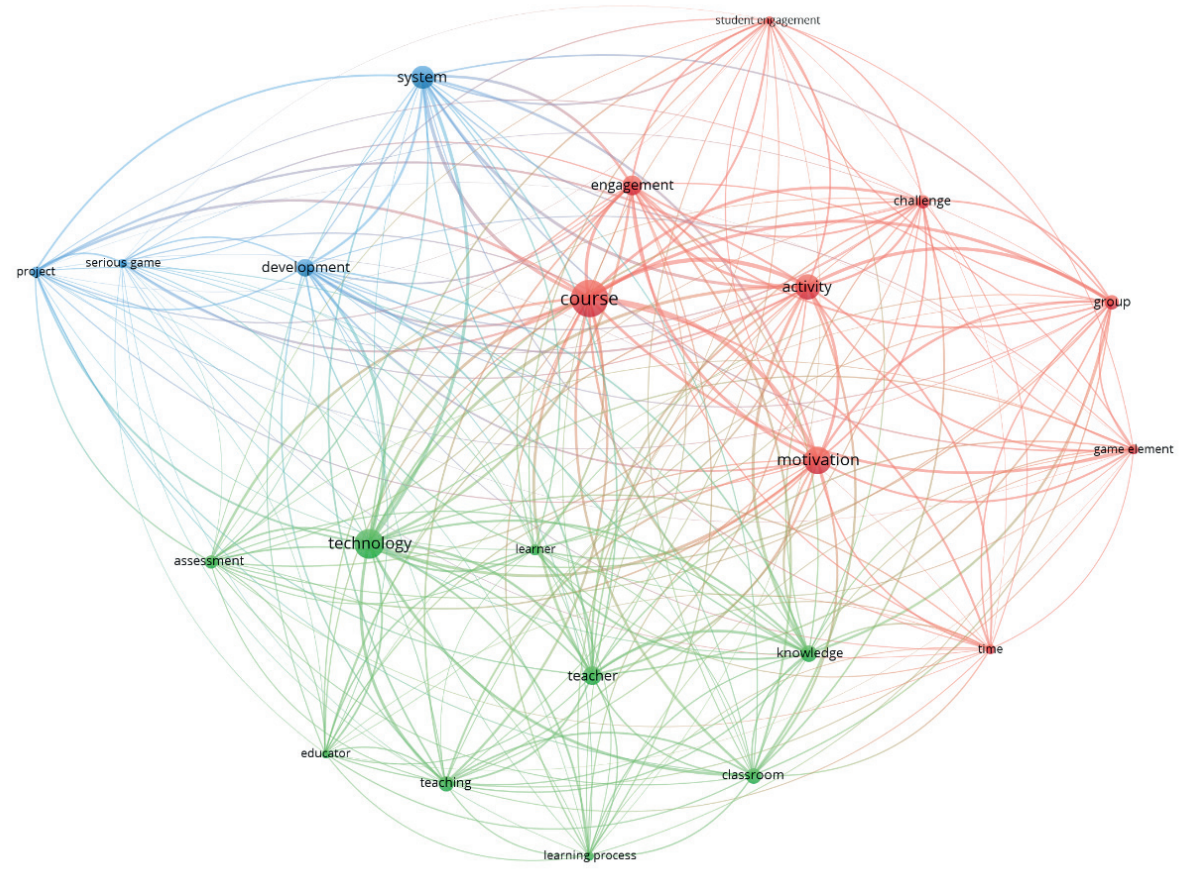

Figure 3. Terms Co-occurrences Network in GHE research filed ( $\mathrm{n}>50)$

the articles with a high index for impact and quality. For this goal, the top 100 highly cited studies were analyzed via citation counts (as of 10 October 2020). By using total citations, the 100 most frequently-cited documents published from 2010 to 2020 were identified. These articles had citation counts ranging from 47 to 130 .

\section{9) the chronological order of the terms occurring in titles and abstracts of the sources}

In order to present a comprehensive overview of 'gamification in higher education' (GHE) literature, we conducted a chronological analysis of the terms that occurred in titles and abstracts of the sources from WoS. Figure 4 depicts the results of the analysis, which was based on the average publication date of the sources where the terms related to GHE research appeared.

As the figure schematically illustrates, literature production progressed in three different periods/ categories. For example, the focus of publications produced in 


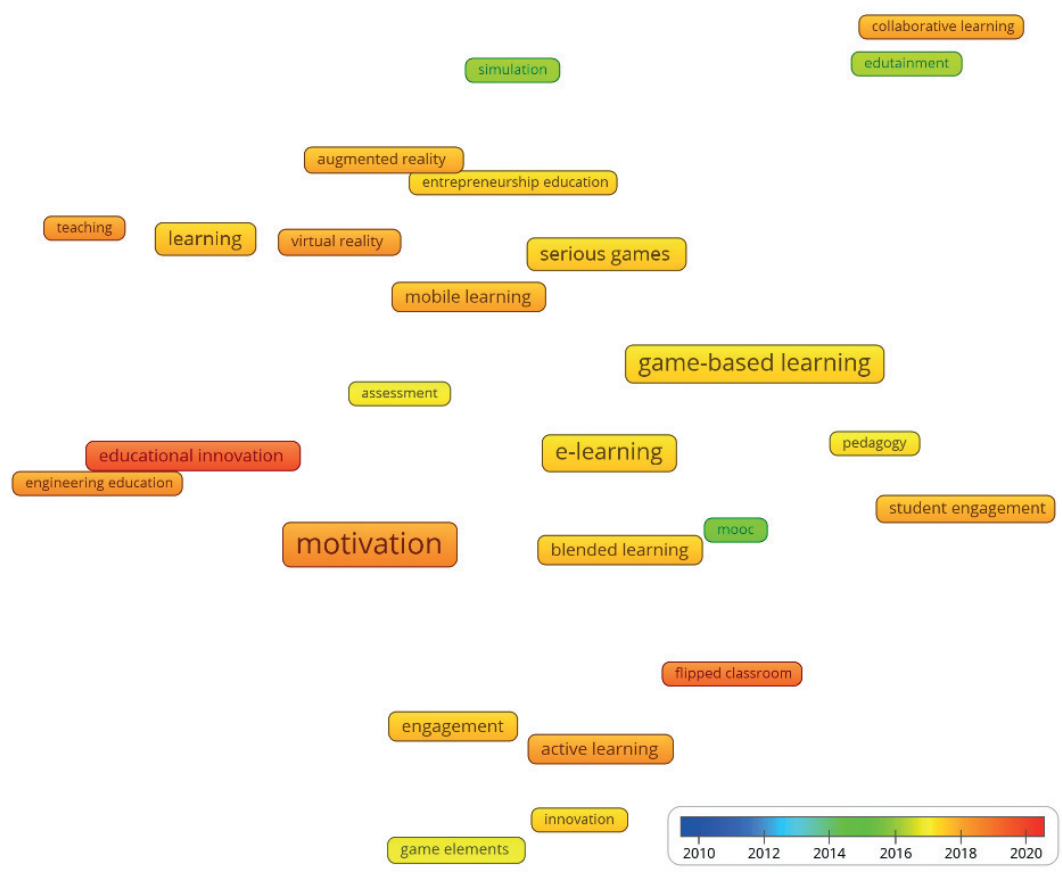

Figure 4. The evolution of research terms

2015 and 2016 was primarily on edutainment, MOOCs, and simulation. Between 2017 and 2018, research in the field focused on e-learning, blended learning, gamebased learning, and mobile learning. By contrast in 2019, the emphasis was put on augmented reality, virtual reality, active learning, and student engagement. Then, more recently, in 2020, the literature has been devoted to educational innovation, flipped classrooms, and motivation

\section{Discussion \& Conclusion}

This study focused on a bibliometric analysis of the research trends of Gamification in Higher Education within the scientific literature in (WoS) during a period of 10 years - 2010-2020. After conducting a comprehensive search process in WoS database and refining the results, we found 432 articles that have been produced by scholars all around the world. 
Descriptive bibliometric analysis revealed that scholars and researchers have published eight different types of texts during this period. Our study showed almost a positive trend in book production, meaning that the number of articles published in the field of education increased over the years. The greatest improvement in the number of published articles took place in 2020 when 107 articles were published (25\% of all published time). As a result of these promotions, many reasons can be given, such as the visible development of ICT, the development of higher education, and teaching and learning strategies. The increase in publications occurred during the last three years of the period - 2018-2020 - including $60 \%$ of all time publications. However, the first 5 years of the period are the least active in publishing the articles (around 20\%).

With regard to citation analysis, it is interesting to note that five articles published in 'Computers and Education' ranked so high on the scale, cited 213 times. 'Lecture Notes in Computer Science' and 'Proceedings of the European Conference on Games-based Learning' are the second and third well-recognized sources among researchers. The strength of co-authorship collaboration depicted Spain and the United Kingdom are the most active ones. On the other hand, the United States, Australia, Canada, Brazil, and South Africa form the second circle of collaboration, being quite active in co-authorship.

The most frequent keywords used by authors are categorized in five different clusters, including (1) Innovative Ways to Motivate and Engage Learners Studies; (2) Cutting Edge Approaches in Learning Assessment Studies; (3) Pedagogical Studies in Gamification; (4) Collaborative and Edutaining Studies; (5) Engineering and Educational Innovation Studies. In addition, the title and terms of the research clustered around three main concepts, including Course, Technology, and System.

This research has implications for both theory and practice. Concerning the effects of the theory, current research provides relevant information to the technical community about the "game" in higher education in several categories. First, this study provides very relevant theoretical contributions as for new techniques in the field of bibliometric research. In addition, this research allows us to develop a field of literature that is commonly presented in higher education. This study provides a clear view of important information about language, place of publication, type of document, organizations, authors, publication sources, countries, and companies. All this information can help researchers better organize their work. In addition, this research identified the most relevant topics in the literature and identified key research lines over the years. Finally, the results shown in this study provide relevant information for teachers and professors about the gamification 
used in higher education. This is because this research can help them make decisions in their daily routine.

\section{References}

Andrew, S. \& Carman, N. (2014). Analysis of Gamification in Education. School of Interactive Arts and Technology, Simon Fraser University.

Barber, C., \& Smutzer, K. (2017). Leveling for success: Gamification in IS education. Boston: Twenty-third Americas Conference on Information Systems.

De Freitas, S. (2018). Are Games Effective Learning Tools? A Review of Educational Games, Journal of Educational Technology and Society, 2 (2), 74-84.

Deterding, S., Dixon, D., Khaled, R., \& Nacke, L. (2011). From game design elements to gamefulness. In Proceedings of the $15^{\text {th }}$ International Academic Mindtrek Conference on Envisioning Future Media Environments - Mindtrek'11.

Ford, J.K., \& Meyer, T. (2013). Advances in training technology: Meeting the workplace challenges of talent development, deep specialization, and collaborative learning. In L.T. Convert (Ed.), The psychology of workplace technology, 43-76. Routledge.

Godwin, J.R. (2014). Games in language learning: Opportunities and challenges. Language Learning and Technology, 18(2), 9-19.

Goethe, O. (2019). Immersion in Games and Gamification. In Human- Computer Interaction Series. Springer International Publishing,107-117.

Kapp, K.M. (2012). The gamification of learning and instruction: Game-based methods andstrategies for training and education. San Francisco, CA: John Wiley and Sons.

Kim, B. (2015). Designing gamification in the right way. Library Technology Reports. American Library Association.

Lister, M. (2015). Gamification: The effect on student motivation and performance at the post-secondary level. Issues and Trends in Educational Technology, 3(2). University of Arizona Libraries.

Majuri, J., Koivisto, J., \& Hamari, J. (2018). Gamification of Education and Learning: A Review of Empirical Literature, The $2^{\text {nd }}$ International GamiFIN conference. Pori. Finland, May 21-23.

Reiners, T., \& Wood, L. (2015). Gamification in Education and Business. Switzerland: Springer International Publishing.

Shute, V.J. \& Ke, F. (2012). 'Games, learning, and assessment', in D. Ifenthaler, D. Eseryel and X. Ge (eds.), Assessment in game-based learning: Foundations, innovations, and perspectives, pp. 43-58, Springer, London.

Yildirim, E. (2016), The effects of gamification-based teaching practices on student achievement and students attitudes toward lessons', The Internet and Higher Education, $33,86-92$.

Zichermann, G. \& Cunningham, C. (2011). Gamification by Design: Implementing GameMechanics in Web and Mobile Apps. Cambridge: O'Reilly Media. 